\title{
Urdimento
}

Revista de Estudos em Artes Cênicas

E-ISSN: 2358.6958

\section{CorpoCidade: O corpo da pessoa com deficiência visual na cidade e suas implicações como Flâneur Cego}

Carlos Alberto Ferreira da Silva

\section{Para citar este artigo:}

SILVA, Carlos Alberto Ferreira da. CorpoCidade: O Corpo da pessoa com deficiência visual na Cidade e suas implicações como Flâneur Cego. Urdimento, Florianópolis, v. 2, n. 38, ago./set. 2020.

DOI: http:/dx.doi.org/10.5965/14145731023820200004

Este artigo passou pelo Plagiarism Detection Software | iThenticate 
CorpoCidade: O Corpo da pessoa com deficiência visual na Cidade e suas implicações como Flâneur Cego

Carlos Alberto Ferreira da Silva ${ }^{1}$

\begin{abstract}
Resumo
O presente trabalho reflete sobre o Corpo da pessoa com deficiência visual na cidade, buscando compreender suas implicações artísticas e políticas no espaço urbano. Por este viés, o texto apresenta uma reflexão a partir da pesquisa Cidade Cega: Uma encenação somático-performativa com atores/performers com deficiência visual na cidade, realizada ao longo do doutorado na Universidade Federal da Bahia, entre os anos de 2014 e 2018 (Ferreira da Silva, 2018). Sendo assim, o artigo descreve sobre a intervenção urbana de dois artistas com deficiência visual, sendo eles, Gilson Coelho e Valmira Noia. Além de trazer para a discussão o termo Flâneur Cego, como resultado da vivência e experiência do Corpo da pessoa com deficiência visual como flâneur na Cidade.
\end{abstract}

Palavras-chave: CorpoCidade. Flâneur Cego. Intervenção Urbana. Pessoa com deficiência Visual.

BodyCity. The Body of the visually impaired person in the City and its implications as Blind Flâneur

\begin{abstract}
The present work seeks to reflect on the Body of the visually impaired person in the City, seeking to understand its artistic and political implications in urban space. Due to this bias, the text presents a reflection from the research Blind City. a somaticperformative urban with visually impaired actors/performers in the city, carried out throughout the doctorate, at the Federal University of Bahia, between 2014 and 2018 (Ferreira da Silva, 2018). Thus, the article describes about the urban intervention of two visually impaired artists, being Gilson Coelho and Valmira Noia. In addition to bringing to the discussion the term Blind Flâneur, as a result of the experience and experience of the Body of the visually impaired person as a flâneur in the City.
\end{abstract}

Keywords: CorpoCity. Blind Flâneur. Urban Intervention. Visually impaired person.

Doutor em Artes Cênicas, encenador, performer, ator, produtor teatral. Professor Dr. Adjunto do Curso de Teatro e do Programa de Pós-graduação em Artes Cênicas da Universidade Federal do Acre (UFAC). carlosferreira1202@gmail.com 
Propõe-se com este artigo discutir processos de configuração espacial na cidade a partir de experiências performativas com atores/performers com deficiência visual, isto é, ações performativas com pessoas que não enxergam ou que possuem baixa visão. Tais ações utilizam o espaço público para realizar intervenções urbanas e performances com finalidade de provocar uma perspectiva sensorial na cidade, bem como de questionar aspectos referentes à acessibilidade e à inclusão desses corpos com deficiência na urbe. Percebe-se que, na cena performativa, aos usos do espaço urbano como meio para ações de intervenção são atribuídos a forma social, política e cultural. A autora Ana Pais (2016, p. 67), no livro O Discurso da Cumplicidade: Dramaturgias Contemporâneas, elucida que a dramaturgia do espaço é simultaneamente uma dramaturgia do espectador, já que questiona e promove relações diferentes entre o espaço e o espectador, a cada performance. Por este viés, a proposta dramatúrgica para estas investigações origina-se do espaço em questão, de uma intervenção urbana gerada pelo não ver e que estimula uma relação do Corpo com a Cidade: o Corpocidade.

Entre os anos de 2014 e 2018, realizei a pesquisa de Doutorado intitulada Cidade Cega: Uma encenação somático-performativa com atores/performers com deficiência visual na cidade (Ferreira da Silva, 2018), realizada na Universidade Federal da Bahia, cuja proposta partiu de uma vivência sensorial com atores e atrizes com deficiência visual. A pesquisa adotou a supressão da visão como estratégia para intensificar a percepção dos outros sentidos na cidade. Sendo assim, em 2015, como resultado do laboratório prático de pesquisa, criou-se a encenação somático-performativa Cidade Cega², cujo objeto de criação se deu por meio da potencialização dos sentidos (tato, audição, olfato e paladar) como meios de percepção da cidade de Salvador - Bahia, sendo o Flâneur Cego uma expressão pioneira cunhada ao longo deste trabalho - como um elemento performativo responsável por acessar as camadas da cidade através da supressão da visão.

Por este viés, neste artigo, a proposta é retomar alguns aspectos refletidos e discutidos ao longo da pesquisa de doutorado e exemplificar por meio de duas

Teaser da encenação somático-performativa Cidade Cega, encenada em 2015. https://www.youtube.com/watch?v=aSadLmq_bVY\&t=5s. Acesso em: 25 de jun. 2020. 
ações realizadas pelos artistas Gilson Coelho (ator/performer com baixa visão) e Valmira Noia (atriz/performer cega) questões que configuram a discussão sobre acessibilidade e inclusão desses corpos na cidade. Tal necessidade de reflexão sobre o espaço urbano e a pessoa com deficiência coaduna com o momento atual, em que muitos corpos estão sendo privados de vivenciarem o espaço urbano em função de um contexto pandêmico. Entretanto, na história, as pessoas com deficiência vivenciam esse estado de forma contínua e corriqueira.

O interesse por resgatar essas performances que antecederam a referida encenação torna-se de suma importância para questionar essas fissuras presentes na própria urbe, além de problematizar a ideia de um espaço enquanto recipiente passivo no qual se dá uma determinada ação cênica.

\section{As intervenções urbanas e o corpo na cidade}

A partir da intervenção urbana, percebe-se as fissuras sociais geradas e concomitantemente suscitadas nos sujeitos praticantes e nos transeuntes. A ideia de intervenção urbana coaduna com a proposta deste fazer, pois na intervenção o lugar é criado (recriado) pelo trabalho de arte. Para a artista e pesquisadora Ines Linke, a intervenção urbana

[...] visa a inserir na experiência do cotidiano uma ampliação da percepção dos elementos e objetos no contexto do corpo social. Nas suas diversas manifestações, as intervenções normalmente estão associadas ao universo da arte pública, tanto em forma de micropoéticas como em grandes instalações artísticas. São inserções no fluxo dos espaços existentes, nas dinâmicas cotidianas de seu uso, de sua rotina e de seus costumes. As intervenções instalam-se como instrumento crítico em relação aos valores e padrões instituídos, em forma de estratégias artísticas que interrompem as organizações espaço-temporais preestabelecidas. (Linke, 2012, p. 19).

Sendo assim a performance, como prática corporal de intervenção urbana, desloca a ideia sedimentada dos espaços, gerando ações que desestruturam a ordem e questionam a estabilidade dos lugares, seus signos, usos e formas. 
A intervenção urbana de Valmira Noia, realizada na Praça Campo Grande, Salvador - Bahia, intitulada Todo mundo tem direito à vida, todo mundo tem direito igual! (2015), se refere ao refrão da letra de música Rua de Passagem, composta por Lenine e Arnaldo Antunes. Esta música foi um dos elementos disparadores da oficina/intervenção e da encenação, realizada com os atores/performers com deficiência visual. A canção trata dos direitos daqueles que consomem o espaço urbano bem como dos direitos de todos com relação ao espaço público, pois a rua, apesar de ser um lugar de passagem, é um lugar de pertencimento e ocupação. Na música, algumas frases enfatizam a importância sobre este lugar de apropriação, lançando um alerta ao sujeito:

Gentileza é fundamental, Não adianta esquentar a cabeça, Não precisa avançar no sinal, Devagar pra contemplar a vista, Menos peso do pé no pedal, Travesti trabalhador turista, Solitário família casal, todo mundo tem direito à vida, todo mundo tem direito igual"3.

No âmbito dos inúmeros acontecimentos da vida urbana, há uma necessidade de compreender os fluxos que se instauram no espaço urbano, saber observar e intervir dentro dessa esfera maciça que é a cidade. Qualquer sujeito que consome a rua utilizando-a para realizar suas atividades diárias clama por gentileza; são por estas razões que Valmira provoca este estado de relação através de sua intervenção.

A artista instalou um varal em braile com a frase: Todo mundo tem direito à vida, todo mundo tem direito igual! Pendurado no corpo da performer na Praça Campo Grande, ao sentir as pessoas se aproximando numa relação de CorpoCidade, Valmira os abordava e perguntava: "O que está escrito no papel?", o que gerava um constrangimento no vidente, que não sabia interpretar aqueles inúmeros pontos em relevo. Após um período de conversação, a atriz/performer dizia o significado da frase e entregava o papel pontilhado em relevo para as pessoas.

Rua de passagem música de Arnaldo Antunes e Lenine, interpretação de Ney Matogrosso. https://www.youtube.com/watch?v=eE3HOTd8e28. Acesso em: 25 jun. 2020. 
Figura 1: Frase Todo mundo tem direito à vida, todo mundo tem direito igual! escrita em braile e utilizada durante a performance, 2015

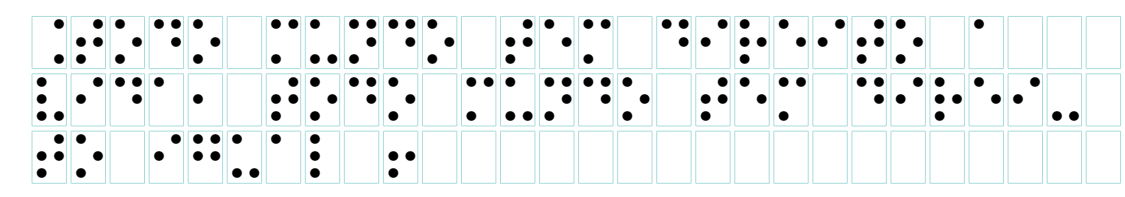

Valmira é completamente cega, perdeu sua visão aos seis anos de idade. No dia da performance, usava um vestido preto e, pendurado em seu corpo, um varal de papéis amarrados em braile. Sua ação era abordar as pessoas e indagar-lhes sobre o que estava escrito. Estima-se o contato com vinte pessoas durante um período de 2 horas de performance. Todas eram videntes e a maioria desconhecia o braile. A ação de Valmira Noia se revelou como processo performativo, cuja intervenção urbana foi composta a partir de suas inquietações com a cidade, que se relacionam diretamente com o seu contexto, principalmente por intensificar o envolvimento entre a performer e o transeunte. A intervenção urbana problematiza a hegemonia entre os próprios sujeitos que vivenciam a rua, friccionando e questionando a ideia de que todos possuem direitos iguais através de uma performer-transeunte cega, que ocupa o espaço urbano, tensionando a funcionalidade prevista e pensada sobre a noção de cidade a partir dos aspectos visuais.

A performance tinha como ação perguntar às pessoas o que estava escrito em braile, fazendo com que o espectador participasse e se perguntasse: "Será que eu preciso saber essa informação?" - fala de uma pessoa que interagiu com Valmira. Além disso, percebeu-se um desconhecimento das pessoas sobre a escrita braile. Para o público abordado, a ação performativa detinha um papel de reflexão, tanto por perceber a intervenção de uma mulher em um estado de indagação quanto por ampliar a compreensão da importância de acessibilizar os espaços da cidade com essa escrita em monumentos públicos, placas de informação e banheiros públicos, dentre tantos outros espaços. Os videntes possuem acesso por meio de informações com imagens e escritas; entretanto, esse espaço é excludente para um grande público vivente e participante da cidade. 
Figura 2 - Atriz/performer Val, Praça do Campo Grande, 2015. Foto: Victor Hugo Sá4

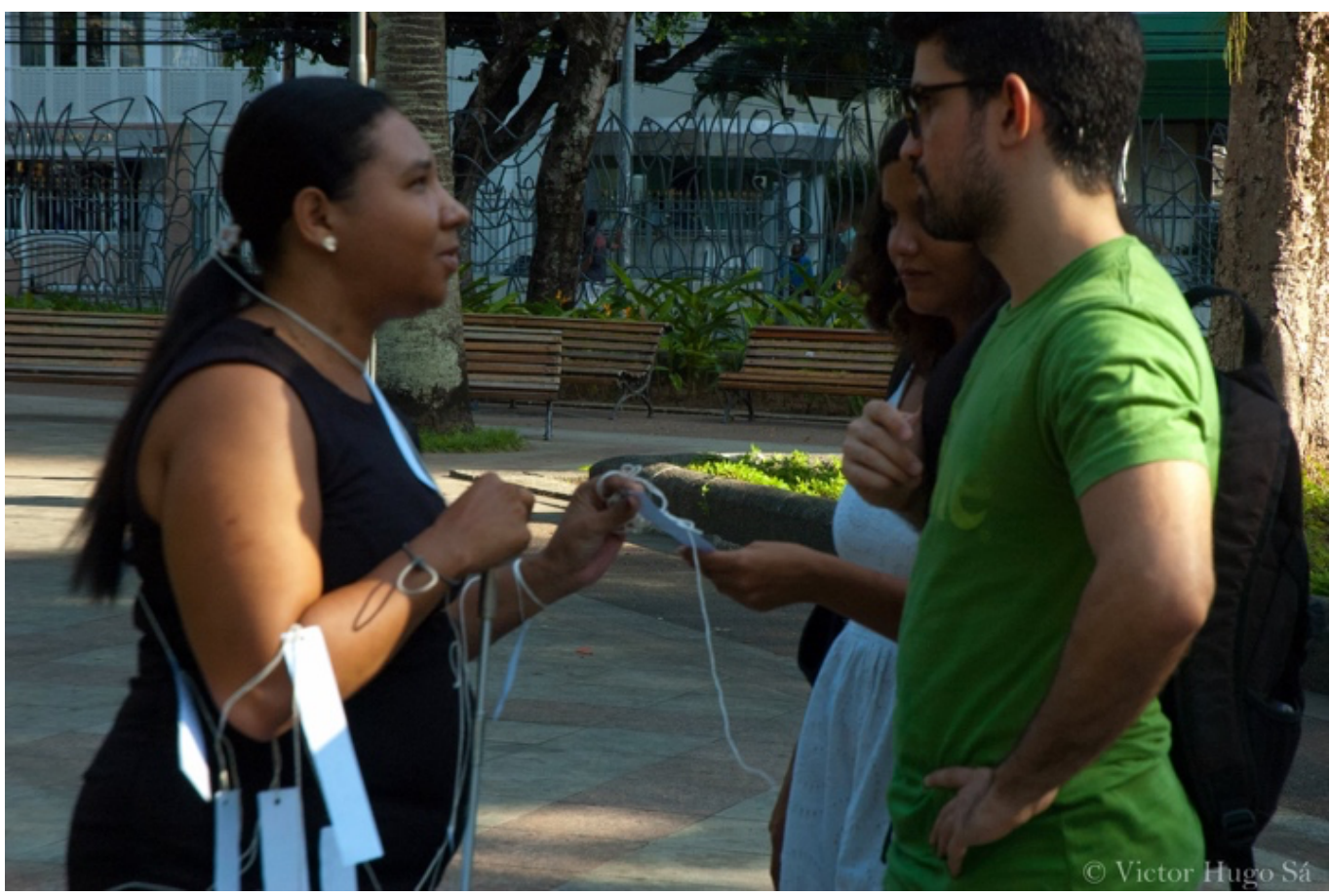

A rua é um lugar de passagem, de ir e vir, de encontros e desencontros, experiências e descobertas. A rua é um lugar do encontro, mas, para isso, algumas ações são importantes para modificar uma rotina fracionada pelo tempo, pelos compromissos e pelo desgaste do cotidiano. A ação de Valmira apresenta o real do que acontece diariamente com milhares de pessoas com deficiência visual, o que é viver em uma cidade cuja linguagem é visual. Os videntes que participaram da ação se depararam com um dado que não correspondia com o contexto que estavam acostumados, dado esse que muitas pessoas vivenciam diariamente numa cidade não inclusiva. Dessa forma, a ação da performer com o texto em braile criava nos espectadores-transeuntes-participantes uma percepção sensível e política sobre um contexto que difere da realidade do sujeito vidente, tornando a performance Todo mundo tem direito à vida, todo mundo tem direito igual! em um estado provocativo e de presença a partir de um corpo-transeunte cego, que

${ }^{4}$ \#paracegover: Val, completamente cega, usa um vestido preto. Em seu corpo há um varal de papéis amarrados em braile, com a seguinte frase: todo mundo tem direito à vida, todo mundo tem direito igual. Na fotografia há um casal (homem e mulher). Atentos, o homem com uma camisa verde à escuta, enquanto a mulher tenta decifrar o papel em braile. Todos estão na Praça do Campo Grande, no fundo da fotografia há bancos e árvores; além de prédios residenciais. 
busca nas ruas o direito de liberdade e de acesso para vivenciar e se apropriar da urbe como qualquer vidente.

Figura 3: Atriz/performer Val, Praça do Campo Grande, 2015. Foto: Victor Hugo Sá5

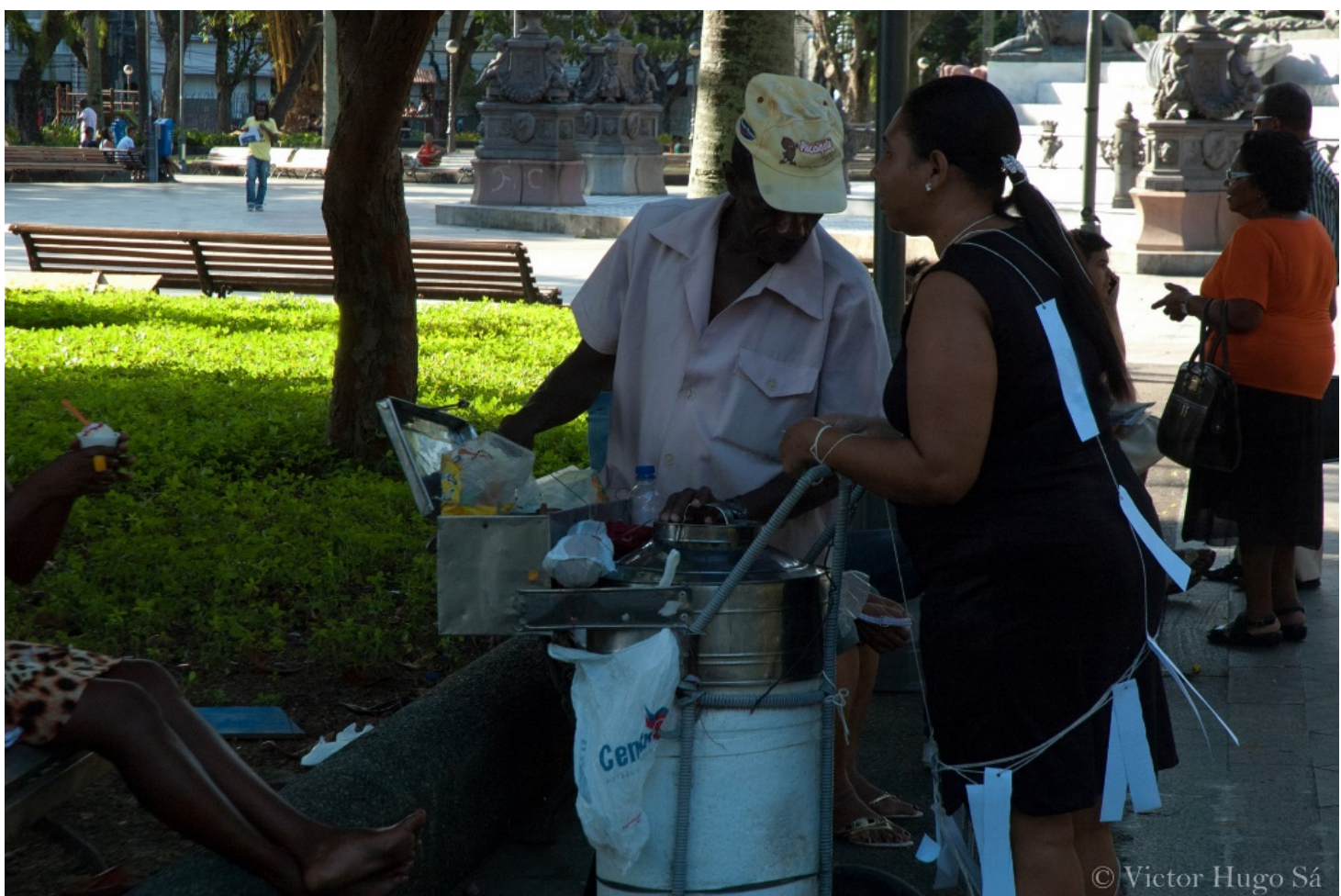

Já a intervenção Acessibilidade não tem preço (2015) de Gilson Coelho consistia em perguntar às pessoas se gostariam de fazer um percurso com os olhos vendados e se guiarem com uma bengala, sozinhos, pela Praça Campo Grande - uma vivência que assemelha ao cotidiano das pessoas com deficiência visual. $O$ intuito era fazer com que os transeuntes explorassem a praça de uma maneira não convencional. A proposta de deslocar o transeunte (o espectador) para uma vivência performática conduzida por uma pessoa cega, que estava na praça, sozinha, causava um estranhamento e ao mesmo tempo um

\#paracegover: Val, completamente cega, usa um vestido preto. Em seu corpo há um varal de papéis amarrados em braile, com a seguinte frase: todo mundo tem direito à vida, todo mundo tem direito igual. $\mathrm{Na}$ fotografia há um senhor negro, de boné, camisa social e com um carrinho de sorvete móvel. Ao lado do senhor, aparecem pernas de mulheres cruzadas sentada no banco da Praça. Atento, o homem com o carrinho de sorvete à escuta, enquanto Val de forma aproximada explica sobre a performance. Todos estão na Praça do Campo Grande, no fundo da fotografia há bancos, monumentos, pessoas e árvores; além de prédios residenciais. 
distanciamento da realidade. Pois, quando uma pessoa vidente se aproximava de Gilson Coelho para the oferecer ajuda, o performer respondia, “Não, obrigado!”, pois o intuito não era ser ajudado, mas propor uma ação com esse sujeito/transeunte. Gilson usava uma camisa preta com o seguinte escrito: "Acessibilidade não tem preço", o que originou o nome da performance. Tinha um apito em seu pescoço e em suas mãos as bengalas, utilizadas como elemento da sua intervenção. A frase estampada na camisa é um reflexo diário do que muitas pessoas passam. Pensar em acessibilidade nas cidades não deveria ser um problema, mas algo natural; entretanto, existe um abismo entre a realidade e o que se almeja, o que se torna custoso ao sujeito que possui uma deficiência.

Além disso, por meio desta ação performativa percebe-se a relação desse corpo com deficiência que vivencia um estado de vulnerabilidade em plena cidade, cotidianamente. Essa relação é diferente daquela do transeunte que transita pelas ruas sem a necessidade do auxílio de um elemento, como ocorre com a bengala no caso das pessoas com deficiência visual. Dessa forma, a relação com a bengala apresenta uma provocação em torno da acessibilidade, pois no discurso de grande parte dos sujeitos que não possuem uma deficiência falar sobre acessibilidade torna-se algo comum; no entanto, na prática, propor ao transeunte uma experiência real, sem ajuda, de modo que o sujeito possa entender minimamente o que se passa com esse corpo com deficiência, coloca-o em um estado de insegurança, fazendo com que o mesmo não consiga ficar muito tempo com os olhos vendados e com a bengala.

Percebe-se que a intervenção urbana se torna política pela prática do fazer. Quando esses corpos, com deficiência, se colocam na rua e os transeuntes se perguntam: "O que está acontecendo?”, esse é o momento político da ação, pois a palavra, quando pronunciada por esses corpos, é dada para sublinhar a ação e não para representar o acontecimento. Pensar sobre a ocupação desses corpos é compreender a importância de como as paisagens e objetos da cidade se formam no corpo dessas pessoas que habitam a urbe, onde a vida urbana do que acontece na cidade não é alheia ou externa ao transeunte, pois esse é também membro desse CorpoCidade. "Um corpo não é vazio. É cheio de outros corpos, partes, 
órgãos, pedaços, tecidos, rótulas, anéis, tubos, alavancas e foles. É também cheio dele mesmo: isso é tudo o que ele é." (Nancy, 2015, p. 87).

Figura 4: Ator/performer Gilson. Praça do Campo Grande, 2015. Foto: Victor Hugo Sá6

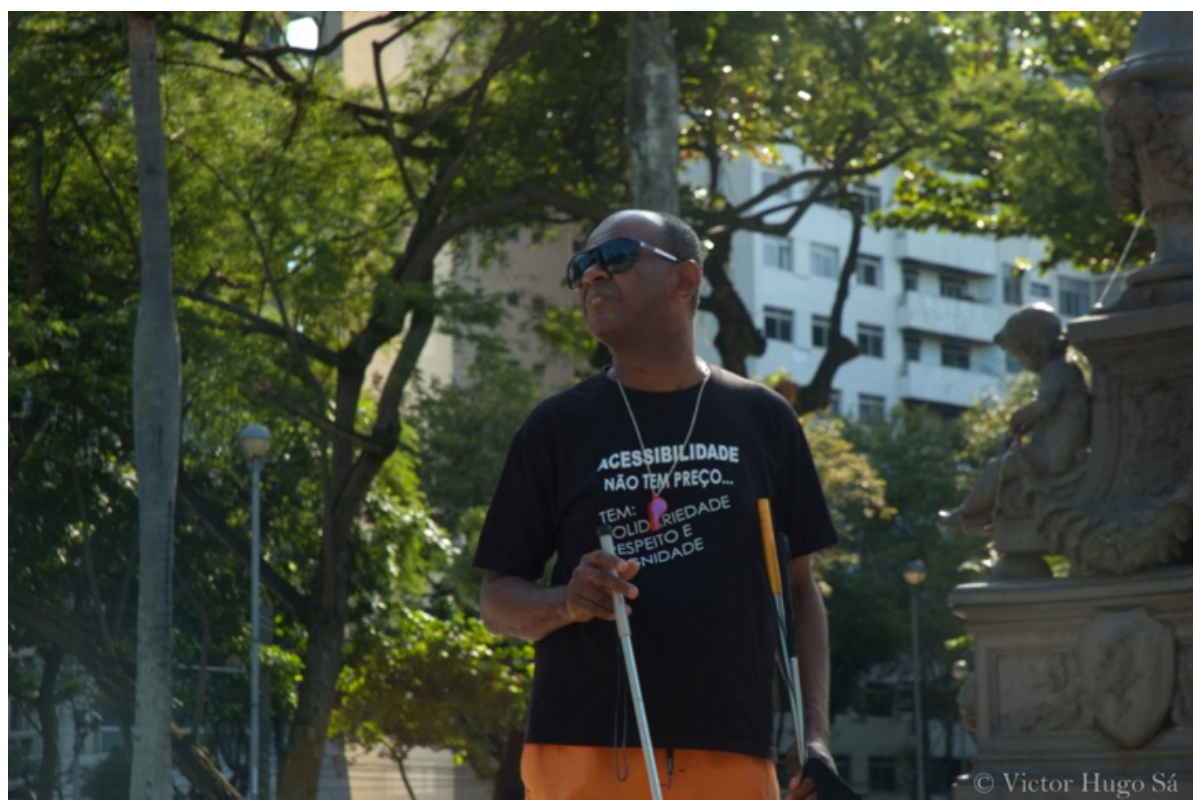

Percebe-se que a intervenção urbana se torna política pela prática do fazer. Quando esses corpos, com deficiência, se colocam na rua e os transeuntes se perguntam: "O que está acontecendo?”, esse é o momento político da ação, pois a palavra, quando pronunciada por esses corpos, é dada para sublinhar a ação e não para representar o acontecimento. Pensar sobre a ocupação desses corpos é compreender a importância de como as paisagens e objetos da cidade se formam no corpo dessas pessoas que habitam a urbe, onde a vida urbana do que acontece na cidade não é alheia ou externa ao transeunte, pois esse é também membro desse CorpoCidade. "Um corpo não é vazio. É cheio de outros corpos, partes, órgãos, pedaços, tecidos, rótulas, anéis, tubos, alavancas e foles. É também cheio dele mesmo: isso é tudo o que ele é." (Nancy, 2015, p. 87).

O trabalho realizado por esses artistas com deficiência Gilson Coelho e

${ }^{6}$ \#paracegover: Gilson está usando óculos escuros e uma camisa da cor preta escrito: “Acessibilidade não tem preço". Pendurado no seu pescoço tem um apito, e em uma das suas mãos ele segura a própria bengala e na outra mão há outras bengalas. Gilson está no centro da fotografia e ao fundo há arvores, poste, prédios residenciais e parte do monumento da Praça do Campo Grande. 
Valmira Noia busca fazer compreender a cidade por esse aspecto de preenchimento, o qual é criado por diferentes sujeitos que, quando somados, formam esse CorpoCidade. Pois, a cidade se soma e se formata a partir de diferentes corpos, e são esses corpos que assumem uma estrutura de ser corpórea e não corpórea. Nas palavras de Jean-Luc Nancy (2015, p. 7), “um corpo expõe uma existência”. Entretanto, percebe-se o quanto esses corpos com deficiência ainda são desconhecidos e inexistentes no âmbito social. Por isso, as ações performativas tensionam sobre a realidade desses sujeitos, gerando um pensamento crítico que constrói e propõe novos meios de compreender a cidade por uma perspectiva "outra", a partir de diferentes corpos que flanam sobre a cidade. As intervenções propõem uma reflexão não só no nível do preconceito ou da desigualdade, mas no nível econômico e social, estimulando uma sensação de pertencimento na relação com o espectador-transeunte-participante, pois a experiência não é apenas um ato efêmero do contato entre os corpos, mas substancial para alavancar discussões importantíssimas na sociedade atual.

\section{A acessibilidade e o espaço urbano: um direito ao Flâneur Cego}

A cidade, a princípio, deveria ser um espaço para a convivência e encontro entre os sujeitos; no entanto, passa a ser estigmatizada como o lugar da violência, da solidão, da não alteridade entre os que a habitam, ou seja, do medo. Esse sentimento se instaura em função de alguns aspectos, como a falta de segurança pública, nas avenidas e ruas, o que não significa a necessidade da presença de mais policiais, mas de iluminação pública; atividades culturais; espaços de convivência; melhorias no transporte público. Pois, a cidade cresce, mas a gestão pública não gerencia, dentro dos padrões necessários, medidas que possam acessibilizar a vida do ser humano.

Acessibilizar corresponde ao inverso do que comumente ocorre, nas cidades, pois a situação atual é de exclusão social, decorrente do descaso do poder público e da desinformação por parte de diferentes setores da sociedade. De 
acordo com o IBDD - Instituto Brasileiro dos Direitos da Pessoa com Deficiência, "as pessoas com deficiência enfrentam diariamente problemas estruturais graves que prejudicam o exercício de sua cidadania e mesmo sua sobrevivência, como a inacessibilidade dos transportes coletivos, o desemprego e a discriminação" (IBDD, 2008, p. 21). Dentro desse pensamento, esse corpo estranho da pessoa com deficiência, para o poder público, é compreendido como um corpo à margem.

Nas palavras de Jean-Luc Nancy (2015, p. 41), a definição de corpo estranho é entendida como toda espécie de "objeto, peça, pedaço ou substância introduzida”, em um determinado espaço, de maneira mais ou menos fortuita, que pode ser considerado um corpo estranho. O autor exemplifica, "na floresta, uma viga de cimento é um corpo estranho, assim como um tamboril de ferro num rio". $\mathrm{Na}$ cidade, pode-se perceber que esse corpo estranho, como menciona Nancy, está estigmatizado na pessoa com deficiência, cuja acessibilidade, na urbe, simplesmente não acontece, a tal ponto que esses corpos vivenciam a prática direta da diferença e, muitas vezes, da segregação.

Entretanto, vale ressaltar que todo corpo é estranho mediante outros corpos, tanto o corpo do ser humano, quanto o corpo constituído na cidade possui suas diferenças. A diferença está presente no tocante ao coletivo, pois é pela diferença que a noção de sociedade e de cidade se instauram. "Ser-estranho é inerente à corporeidade". Para Nancy, o corpo estranho estende e expande a noção da diferença corporal. Isto é, o corpo estranho ou corpo com deficiência possui uma dimensão de potência que se soma ao contexto e as condições necessárias para viver.

A sua dimensão, no entanto, todas as suas dimensões, constituem assim distanciamentos: os outros corpos devem afastar-se. Esse afastamento abre as condições de suas relações - de seus contatos, de suas confrontações, de seus olhares, escutas, gostos e atrações. (Nancy, 2015, p. 43).

Portanto, o CorpoCidade se soma, quando a vivência e a relação de ser e estar na cidade, é compreendida pelo direito de usufruir das condições dadas a esses corpos. 
Por esse viés, a intervenção urbana de corpos de pessoas com deficiência visual nos espaços urbanos apresenta aspectos relacionados à cidade e destinase a reflexões através de uma perspectiva artística; mas, também política. Dessa forma, os estudos realizados ao longo do período do doutorado, que resultam na tese supracitada, buscaram enfatizar estas lacunas, estas fissuras que estão presentes no pensamento urbano e do corpo. Torna-se necessário falar sobre esta cegueira que está tão presente na cidade. Busca-se, sobretudo, compreender a cidade como extensão do próprio corpo, fazendo da cidade um lugar de ocupação, um CorpoCidade, que revela o corpo coletivo. Nas palavras de Sonia Rangel, "A casa aqui se estende além do corpo do sujeito, é a cidade, e uma espécie de amor novo, mais amplo. É o corpo do labor, da obra, que lentamente se constrói. Fundese, à cidade, a cidadã, como devaneio do diálogo." (Rangel, 2005, p. 20).

Por isso, o ato de usufruir da cidade com liberdade de andar, de caminhar, de ter autonomia de ir e de ocupar os diferentes lugares é um direito social e público, e corresponde ao Estado possibilitar essas condições a todos os transeuntes. Dessa forma, a ação de flanar é para além de um roteiro e de um único sentido como a visão, pois são pelas caminhadas que o sujeito se perde, é perdido que ele se encontra, e do encontro ele se acha. Esta vagabundagem, como salienta João do Rio no livro A Alma Encantadora das Ruas (1908), possibilita esse devaneio sem destino a ter um encontro consigo e, principalmente, com os sentidos, pois amplia o corpo a viver experiências sem objetivos, apenas vivê-los. Em função disso, o sujeito transeunte com deficiência visual, que não possui uma objetividade na chegada, se possibilita a fazer, a viver, a experimentar sensações, durante o percurso, que raramente aconteceria com um sujeito que vivencia uma prática da repetição cotidiana.

O mundo do flâneur é aquele onde o sujeito caminha pela urbe, observa/sente os acontecimentos ao seu redor e vivencia o cotidiano. "Sem pressa, apreende cada detalhe sem ser notado e busca uma nova percepção da cidade. 0 que importa para o flâneur é perder-se, mergulhar em meio à multidão e vagar pelas ruas da cidade sem objetivo ou intencionalidade" (Takaki, 2015, p. 89). desejo de flanar por entre as ruas faz com que o sujeito explore os espaços ora 
de conforto, ora da selva da cidade - exploração movida de reflexão, de sentimento e de verdades. Existe uma ingenuidade por parte do sujeito investigador, pois há um cuidado, uma atenção ao lugar ora desconhecido, ora revisitado. Com isso, cada passo é uma descoberta, cada entrada é possibilidade para futuras experiências.

$O$ ato de andar sem rumo e de perceber os estímulos do corpo de forma anômala faz com que o sujeito se mova através dos sentidos, pois são eles que enviam as informações para o cérebro. Se, o sujeito se move por meio dos sentidos, logo, se torna um ser sensível. Para Maurice Merleau-Ponty (1999, p. 32), o sensível

é aquilo que se apreende com os sentidos, mas nós sabemos agora que este 'com' não é simplesmente instrumental, que o aparelho sensorial não é um condutor, que mesmo na periferia a impressão fisiológica se encontra envolvida em relações antes consideradas como centrais. (Merleau-Ponty, 1999, p. 32).

Ou seja, há uma comunicação entre o sensível e o sentido, de modo que o sensível compreenda as funções dos sentidos no contexto do sujeito. Na flanância de um sujeito, independentemente de se há uma deficiência ou não, os sentidos são as vias para acessar o sensível da cidade. Os sentidos, em suas esferas de ligação com o mundo, contribuem para que o flâneur caminhe para lugares que até então não tinham sido idealizados ou se concretizados, acionando os diferentes sentidos a fim de contribuir com a flanância na cidade de uma forma sensível. Em defesa dos sentidos, Merleau-Ponty (1999, p. 178) atribui a eles e, em geral, ao próprio corpo, um conjunto de mistérios que, sem abandonar sua individualidade e sua particularidade emite "para além de si mesmo, significações capazes de fornecer sua armação a toda uma série de pensamentos e de experiências". O sujeito se conecta com o mundo pela via do sensível; assim, as propriedades sensoriais do sujeito, juntamente com o corpo da cidade, constituem uma harmonia. Dessa forma, o olhar, o tato e todos os outros sentidos "são em conjunto as potências de um mesmo corpo integradas em uma só ação”. (MerleauPonty, 1999, p. 426). 
Mesmo identificando a potência e importância dos sentidos, sabe-se que são movidos por limites. Em algumas pessoas, o próprio sentido se torna um limite na falta concreta deste importante suporte que integra um corpo. Jean-Luc Nancy (2000, p. 32) apresenta uma provocação contundente no âmbito dos sentidos, principalmente por identificar que no próprio sentido há um limite. No livro Corpus (2000), algumas questões são abordadas pelo autor: "Por que é que existe esta vista que não vê os infravermelhos? Estes ouvidos que não ouve o ultrassom? Por que é que em cada sentido há limites, e entre todos os sentidos um muro?”. Tais indagações se reverberam no âmbito das pessoas com deficiência, pois há um limite presente em suas ações, algumas vezes impostas pelo próprio corpo e outras pela sociedade.

Portanto, na experiência de flanar por uma cidade sensível onde os sentidos possam ser acionados ao longo da caminhada, necessita-se que o flâneur, dentro desse processo que é pessoal se torne, se transforme, se identifique como um sujeito sensível. Mediante as inúmeras referências relacionadas ao flâneur, para Charles Baudelaire o flâneur pode ser reportado como observador, filósofo, investigador, curioso, dentre outras denominações: “Às vezes ele é um poeta; mais frequentemente aproxima-se do romancista ou do moralista; é o pintor do circunstancial e de tudo o que este sugere de eterno" (Baudelaire, 1996, p. 13). Nesse espaço, percebe-se uma coisa, o sensível, classificado como um adjetivo, mas não como um substantivo. Dessa forma, uma das atribuições relacionadas ao flâneur é a importância de compreendê-lo como um sujeito sensível, curioso, investigador e, sobretudo, autônomo. Sendo assim, a noção do flâneur está atrelada ao sujeito que observa, ou seja, que utiliza da visão como ponto de partida para os seus interesses, através do desenvolvimento da cidade moderna e pósmoderna.

A visão torna-se a palavra-chave do sujeito que flana pela cidade. É como se construíssemos, pela ótica e pela geometria, o fragmento daquele contexto da flanância cuja imagem se forma a cada momento pela retina. Esta afirmação se define como um dos princípios; no entanto, a complexidade da flanância está atrelada à relação do sujeito com a cidade através dos sentidos, uma vez que é 
por meio deles que o sujeito sensível aciona outras capacidades para explorar a urbe. Logo, transpondo e despertando outras abordagens sensíveis de como explorar o espaço da cidade.

Dessa forma, os meios de acesso ao mundo da descoberta, do envolvimento, do flanar e do sentir a cidade ultrapassam o limite do olhar e acionam outras maneiras de vivenciar, mesmo sem olhar/enxergar. Muitas vezes acredita-se que através da visão todas as informações são apreendidas, desde o (re)conhecimento dos caminhos e do trajeto às experiências e limites. Entretanto, em função da necessidade moderna do sujeito realizar inúmeras atividades ao mesmo tempo, sabe-se que a relação entre sujeito e cidade vem-se tornando distanciada. Assim, andar pela cidade e pensar, filosofar e refletir tornou-se, infelizmente, privilégio para alguns.

Mas, dentro deste paradigma do mundo contemporâneo alguns preceitos se tornam as razões de muitos, a ponto de dizerem que nunca possuem tempo. Acredita-se na importância de repensarmos outras maneiras de perceber a cidade e, assim, possivelmente, refletir e possuir a compreensão de como interagir com a cidade, tornando-se o início do estudo em questão. Por isso, o interesse por apresentar a noção do flâneur a partir de uma diferenciação do sujeito comum, pois, em alguns casos, muitos se apegam a uma experiência de ver a cidade de uma forma rápida e fugaz, reparando apenas o visível do objeto. Outros, como os flâneurs, buscam olhar o invisível da cidade: uma experiência mais contemplativa.

Por esse viés, o intuito de propor uma provocação sobre os agentes e estudiosos acerca do flâneur me inquieta. Ainda preciso compreender o quanto a perspectiva da experiência se concentra na visão. Mas, ao modificar esta lógica e adentrar em um pensamento estético, político e contemporâneo sobre o sujeito autônomo, como pensar e discutir a noção de "flanância" a partir de um sujeito com deficiência visual, que deixa a porta da casa para aprender/experimentar/desfrutar da cidade. Poderíamos pensar o "Flâneur Cego"?

Ao me deparar com o sujeito querendo atravessar uma rua e perceber o tempo que uma pessoa com deficiência visual poderia gastar ao participar de uma 
performance em que uma mulher utiliza do seu corpo; perguntando se todos possuem direitos iguais, provocando o transeunte vidente a repensar a compreensão de cidade; ao ver um performer negro com deficiência visual, sugerindo o uso de vendas e bengalas para fazer um percurso sozinho em uma praça e tantas outras questões sobre o tema da acessibilidade, torna-se de suma importância rever e repensar a noção da ideia de flâneur, pois a pessoa com deficiência visual contempla a cidade, se emociona com a cidade, vivencia a cidade. Essas são pessoas que possuem livre arbítrio para tomarem suas próprias decisões e criarem suas histórias, bem como fazer parte da História.

Giampaolo Nuvolati trabalha com a noção de flâneur apresentada por Walter Benjamin em suas pesquisas sobre as "passagens" de Paris, iniciadas no século XIX, para designar os poetas e os intelectuais que passeavam e observavam criticamente os comportamentos dos indivíduos (Nuvolati, 2013, p. 1). Para Emika Takaki (2015, p. 90), em seu texto Corpo-Cidade: coreografias urbanas, a Paris do século XIX torna-se a cidade da experiência urbana, pois os encantos apresentados pela poesia de Baudelaire compreendem uma cidade lírica que faz do poeta um fisionomista da imagem urbana. Benjamin explica que a percepção do flâneur não é apenas do olhar, mas o experimentado e vivido. Por isso, "a rua conduz o flanador a um tempo desaparecido. Para ele todas são íngremes”. (Benjamin, 1989, p. 185).

Dessa forma Baudelaire, como aponta Benjamin (1989), percebeu em meados do século XIX que algo novo se iniciava na cidade pela arte da poesia, pois havia uma proximidade do artista com o espaço urbano no ambiente da cidade que se instaurava devido às conquistas industriais que ocorriam em Paris. Uma das formas de compreensão deste futuro se deu a partir da observação realizada pelo poeta. Para a época, o novo gerava inquietações que envolviam o homem moderno, a fim de compreender as modificações da cidade frente a tantas transformações. Baudelaire, em meio à multidão moderna, evidenciava uma nova perspectiva de identificar as mudanças: a do flâneur. O livro Le flâneur postmoderne de Jieun Shin (2013) primeiramente concerne a uma questão de identidade, uma maneira individual de viver. Citando Benjamin, Shin diz que o flâneur, nas palavras de Baudelaire, “ama a solidão na multidão”. (Shin, 2013, p. 16). 
Para Baudelaire (1996), o flâneur se referencia no estranhamento, não na aceitação. Sendo assim, o flâneur está entre a multidão e a classe burguesa consumidora que estranha a evolução ao mesmo tempo em que reflete sobre os ocorridos. Apesar de identificar fortemente a presença do "olhar e ver" nos textos e nas poesias de Baudelaire, o poeta deixa margem para compreender o "perfeito" flâneur a partir de outras perspectivas; pois, para o observador apaixonado é um imenso contentamento fixar residência no numeroso, no ondulante, no movimento, no fugidio e no infinito. Estar para além da porta é sentir-se em casa, onde quer que se encontre; é ver o mundo, estar no centro do mundo e permanecer oculto ao mundo por meio do corpo observador.

O autêntico flâneur é aquele que se completa com os seus sentidos e seus pensamentos oriundos da rua, da cidade. A cada movimento do corpo, a cada passo, o andar ganha uma potência crescente; os sentidos se conectam com o corpo, ao mesmo tempo, o corpo se conecta com a cidade. Mesmo que o sujeito não acesse a urbe pela visão, o corpo se adapta a outras maneiras de sentir a cidade. Os flâneurs são, aparentemente, solitários. Nas palavras de Jieun Shin (2013), essa solidão não é um resultado negativo da sociedade moderna, mas no caso do flâneuré uma escolha ou um estilo de vida. Porém, em algumas situações, para o Flâneur Cego como um dado compreendido neste estudo, há uma necessidade obrigatória de haver uma outra pessoa, no intuito de ajudar em momentos que podem se tornar arriscados para a própria vida como, por exemplo, atravessar uma rua.

Por essa via, ao andar sem destino o flâneur busca captar recortes/informações/sensações do mundo externo da cidade, já que a relação interior do mundo do sujeito atenta-se com a casa, bem como com o próprio interior do corpo. Assim, as relações interior e exterior fundem-se, de modo que o corpo da cidade, somado ao corpo do sujeito que flana, torna-se um CorpoCidade: um se completa no outro. Essa complementação pode ser respondida através das palavras de Benjamin, pois o flâneur não possui somente a cidade, mas a sua história: "ele despreza a história convencional que afasta do concreto, mas fareja na história a cidade e a cidade na história” (Benjamin apud Rouanet, 1992, p. 50). 
Dessa forma, "cada rua para ele é uma ladeira que desce em direção ao passado - o dele e o da cidade" (Benjamin apud Rouanet, 1992, p. 51). Ou seja, a noção de CorpoCidade se estabelece na soma do interior com o exterior, por esses motivos relacionados ambos à ideia de que qualquer sujeito é um flâneur, o que nos remete à imbricação CorpoCidade, onde os limiares entre o sujeito e a cidade são conectados pelos fios que os interligam no espaço urbano.

O texto Le flâneur dans l'espace urbain ("O flâneur no espaço urbano"), de Giampaolo Nuvolati (2016), nos apresenta uma perspectiva ousada da relação entre o flâneur do século XIX e o do contexto atual. O autor salienta que inúmeras abordagens foram utilizadas no final do século XIX e no século XX sobre os sujeitos que utilizavam a flanância como abordagem para descobrir a cidade, andar pela multidão, escrever sobre os lirismos e as poéticas e, sobretudo, compor palavras que geravam narrativas e poesias através das flanâncias. Atualmente, os interesses de realizar essas descobertas foram se transformando com a utilização de recursos tecnológicos que começaram a fazer parte do trajeto do flâneur pósmoderno.

$\mathrm{Na}$ realidade, esses novos sujeitos que flanam pela rua aderem a esses recursos. De acordo com Nuvolati, da rua para a casa os aplicativos, os celulares e os computadores são agregados e utilizados por pessoas, e o flâneur possui uma liberdade de criar suas próprias medidas de apropriação. Entretanto, com os atuais recursos o mistério, a imaginação e a fantasia, as questões, os problemas e algumas curiosidades são rapidamente respondidas em frações de segundos; e os trajetos são resolvidos por meios de celulares que possuem aplicativos e mapas disponíveis para se localizar.

Em determinadas situações, o desbravador utiliza tais recursos a fim de facilitar a jornada ou contrapor o trajeto sugerido; no intuito de conhecer outras possibilidades, contraria a indicada pelo aplicativo, por exemplo. Com relação ao Flâneur Cego, as presentes tecnologias contribuem para que o sujeito se localize, descobrindo em qual região da cidade o mesmo se encontra, bem como as possibilidades de transportes que são disponíveis a ele. Por esse aspecto, as tecnologias portáteis se tornam de suma importância para um sujeito que quer 
flanar na solidão, pois, na cidade, em sua maioria as placas de sinalização, com endereços e informes, são visuais, o que dificulta à pessoa com deficiência visual saber o lugar e o onde se encontra, conforme salientado nas duas performances. Há aqueles que se recusam a se subverterem a essa prática contemporânea. Mesmo com as inovações, a cidade é um infinito formado por composições, contextos e investigações dos sentidos; pois, com as intervenções realizadas diariamente na urbe essas mudanças afetam tanto o corpo do sujeito quanto a cidade.

Portanto, a reflexão sobre o contexto atual, nos faz admitir que a cidade ainda proporciona segregação e falta de espaço e de autonomia aos diferentes sujeitos que a ocupam. Por isso, para compreender a importância de vivenciar a cidade e os espaços existentes de consumo coletivo, torna-se de suma necessidade apresentar condições de acessibilidade ao transeunte com deficiência, oferecendo condições arquitetônicas, comunicacionais e tecnológicas para acessar a cidade de forma fluida e autônoma.

Para isso, algumas considerações precisam ser ressaltadas, o direito à cidade deve ser praticado por qualquer pessoa, como o direito à autonomia e ao acesso aos bens culturais e sociais. Dessa forma, faz parte do papel do Estado fiscalizar os impactos gerados, através dessas construções que afetam diariamente o corpo da cidade, bem como o corpo do sujeito que usufrui da cidade. Necessita-se que as leis de mobilidade urbana façam parte do contexto diário das cidades, propiciando condições reais para que as ruas, as calçadas e as praças tenham os aparatos precisos, de tal forma que a pessoa com deficiência possa flanar e usufruir desses espaços como qualquer outro sujeito. Pois, o direito à cidade são para todas as pessoas, independente de sexo, de raça, de corpo; mas, para que isso ocorra, é preciso pensar a função sintomática do Flâneur Cego no espaço da rua, pois o corpo do sujeito cego imprime um alerta sobre a necessidade de se fazer valer as leis e as normas; o Flâneur Cego é um imperativo para que as políticas públicas possam se fazer presente na acessibilidade urbana; o Flâneur Cego está na multidão, nas estações de metrô, nas rodoviárias, nas praças, nas calçadas, nos limiares da cidade, estranhando a evolução ao mesmo tempo em 
que reflete sobre as ações ocorridas com o corpo da cidade e do sujeito.

Por isso, os exemplos das performances Acessibilidade não tem preço de Gilson Coelho e Todo mundo tem direito à vida, todo mundo tem direito igual! de Valmira Noia nos questionam sobre os aspectos referentes ao contexto da própria arte e das políticas de acessibilidade presentes nas produções artísticas. Ou seja, as ações performativas não problematizam apenas as fissuras da cidade, mas da própria arte, a partir do momento em que esses corpos assumem de forma veemente papéis que nos fazem refletir sobre o contexto artístico por um viés político. Sendo assim, a ação performativa realizada pelos performers desloca o olhar do transeunte vidente a estranhar a presença desses corpos, pois, no cotidiano, as pessoas estão mais dentro de si, mesmo quando estão fora, caminhando pelo espaço urbano. No entanto, devido as inúmeras questões de tempo, em função da "vida agitada", acabam não observando os diferentes corpos que flanam e compõem o espaço urbano. Dessa forma, a presença desses corpos estranhos, mas que são "corpos vestidos ou providos de marcas significantes forma o que chamamos de sociedade. Assim entendida, a sociedade não deve ser especificada como o conjunto de relações "na exterioridade”' (Nancy, 2015, p. 14). Ou seja, como salienta Nancy, a sociedade deve ser entendida como um regime vigente de uma simbolicidade, de um relação de exterioridade que são próprias do estado de natureza, mas dentro da condição humana. Por esse viés, cabe ao artista com deficiência friccionar e tensionar essa realidade que destoa do sujeito normativo daqueles que vivenciam um estado de invisibilidade, compondo mais em uma esfera individualizada, do que coletiva, diante de uma sociedade capitalista.

Por essa razão, o Flâneur Cego torna-se um termo político, cuja compreensão se estabelece pela vivência do sujeito com deficiência visual na cidade, buscando e possuindo os mesmos direitos de consumir o espaço urbano como os videntes, mas tensionando a funcionalidade do próprio espaço urbano frente ao desenvolvimento urbanístico. O Flâneur Cego é um sujeito urbano que vivencia o espaço e suas limitações, mas evidencia nele sua funcionalidade e os problemas que neles se intensificam com a falta de acessibilidade. O flâneur de Walter 
Benjamin e de Charles Baudelaire partia da descrição e da experiência de poetas e intelectuais que utilizavam do olhar como meio para narrar os impactos e identificar as poesias que surgiam na cidade em pleno estado de transformação; já o Flâneur Cego transpõe o olhar para o corpo, buscando uma conjugação entre - Corpo e a Cidade, adotando a supressão da visão como estratégia para intensificar a percepção dos outros sentidos na cidade e registrar os impactos que o desenvolvimento ocasionam de forma positiva e negativa no corpo. Por fim, diante dessas inquietações, surgem perguntas: quanto tempo levará para essa condição de cidade sensível/acessível se tornar real a todas as pessoas com deficiência? Quando a cidade será um direito de todas as pessoas?

Para finalizar, trago como questão o título da performance de Valmira Noia, como uma provocação a nós, leitores; a nós, pesquisadores; a nós, artistas; e a nós, seres políticos: Todo mundo tem direito à vida? Todo mundo tem direito igual?

\section{Referências}

BAUDELAIRE, Charles. Sobre a modernidade. São Paulo: Paz e Terra, 1996.

BENJAMIN, Walter. Paris do Segundo Império. In: Charles Baudelaire: um lírico no auge do capitalismo (Obras escolhidas, Vol. III). São Paulo: Brasiliense, 1989.

FERREIRA DA SILVA, Carlos Alberto. Cidade Cega: uma encenação somáticoperformativa com atores/performers com deficiência visual na cidade. Tese (Doutorado em Artes Cênicas) - Universidade Federal da Bahia. Salvador - Bahia, 2018.

IBDD - Instituto Brasileiro dos Direitos da Pessoa com Deficiência. Inclusão social da pessoa com deficiência: medidas que fazem a diferença. Rio de Janeiro: IBDD, 2008.

LINKE, Ines. Fiç̧ões: arte, natureza, cidade. Tese (Doutorado em ) - Universidade Federal de Minas Gerais, Belo Horizonte, 2012.

MERLEAU-PONTY, Maurice. Fenomenologia da percepção. Tradução de Carlos Alberto Ribeiro de Moura. São Paulo: Martins Fontes, 1999.

NANCY, Jean-Luc. Corpus. Tradução de Tomás Maia. Lisboa: Vega Passagens, 2000. 
NANCY, Jean-Luc. Corpo, fora. Tradução de Márcia Sá Cavalcante Schuback. Rio de Janeiro: 7Letras, 2015.

NUVOLATI, Giampaolo. Le flâneur dans l'espace Urbain. Géographie et cultures [En ligne], 70 | 2009, Paris, 2016.

RANGEL, Sonia. CasaTempo. Salvador: Solisluna, 2005.

RIO, João do. A alma encantadora das ruas. Rio de Janeiro: Fundação Biblioteca Nacional, 1908.

ROUANET, Sérgio Paulo e PEIXOTO, Nelson Brissac. É a cidade que habita os homens ou são eles que moram nela? Dossier Walter Benjamin, Revista USP, São Paulo, v.1, n. 15, set/out/nov. 1992, p. 49-75.

SHIN, Jieun. Le flâneur postmoderne: Entre solitude et être-ensemble. Paris: CNRS Éditions, 2014.

TAKAKI, Emika. Corpo-Cidade: coreografias urbanas. Trama: Indústria Criativa em Revista, v. 01, 2015.

Recebido em: 30/06/2020

Aprovado em: 06/08/2020 